\section{Multiplicidade, heterogeneidade e coordenação: a produção do cuidado em alimentação e nutrição a partir das práticas de apoio matricial}

\author{
Multiplicity, heterogeneity, and coordination: the \\ production of food and nutritional care based on \\ inter-consultation support practices
}

\author{
Multiplicidad, heterogeneidad y coordinación: \\ la producción del cuidado en alimentación y \\ nutrición a partir de las prácticas de apoyo \\ matricial
}

Lilian Miranda Magalhães 1

Ligia Amparo-Santos 1 doi: $10.1590 / 0102-311 \times 00127819$

\author{
Correspondência \\ L. M. Magalhães \\ Universidade Federal da Bahia. \\ Rua Basilio da Gama s/n, Campus Canela, Salvador, BA \\ 40110-907, Brasil. \\ lilianmirandam@gmail.com
}

1 Universidade Federal da Bahia, Salvador, Brasil. do Núcleo Ampliado de Saúde da Família e Atenção Básica. Os dados foram analisados em interlocução com Deleuze e Guattari, Túlio Batista Franco e pesquisadores vinculados à Teoria Ator-Rede como Annemarie Mol e John Law. A investigação identificou que a produção do cuidado em alimentação e nutrição emerge de articulações entre múltiplos atores em redes dinâmicas e interligadas. As práticas de cuidado estão fortemente ligadas aos modos de inserção da alimentação no cotidiano de profissionais e usuários, expondo paradoxos nas relações de apoio mútuo e ampliação do acesso a alimentos nos territórios. Compondo a heterogeneidade material na mediação das interações, a comida destacava-se pela potência em provocar conexões. A comensalidade mobilizava subjetividades pelo uso de modos emocionais e sensoriais de conhecer, aprender e cuidar. Vivenciando tensões inerentes às relações entre micropolítica e macropolitica, as apoiadoras matriciais, em conjunto com os demais atores, coordenavam as redes para a produção do cuidado em alimentação e nutrição em um processo aberto, dinâmico, provisório, profuso e compartilhado. Tal compreensão pode contribuir para posicionamentos mais ativos e conscientes, que avançam no sentido da corresponsabilidade na luta pela implantação e execução de políticas públicas que oportunizem a garantia da Segurança Alimentar e Nutricional à população.

Alimentos, Dieta e Nutrição; Atenção Primária à Saúde; Educação em Saúde 


\section{Introdução}

O cenário global de transições demográfica, epidemiológica e nutricional tem desafiado os sistemas de saúde a desenvolver novos modelos de atenção e práticas resolutivas de cuidado à população. A alimentação, identificada como um dos principais determinantes modificáveis, associada às doenças crônicas não transmissíveis, excesso de peso e obesidade, foi enquadrada no critério de melhor relação custo-efetividade e, por seu turno, passou a ser objeto de pesquisas e intervenções. Ao enfocar o estilo de vida, tais investigações expuseram aspectos de uma dimensão complexa e transversal do cuidado, ampliada pela assunção do Direito Humano à Alimentação Adequada (DHAA) e da Segurança Alimentar e Nutricional, como requisitos para a proteção e promoção da saúde e qualidade de vida 1,2.

Nesse contexto, a atenção primária à saúde (APS) foi apontada por órgãos internacionais como lócus estratégico para a oferta de cuidados primários relativos à alimentação pela proximidade com as questões alimentares e nutricionais das populações em seus territórios, e pelos princípios e diretrizes que a norteiam: universalidade, integralidade, longitudinalidade, continuidade, dentre outros 2,3.

No Brasil, desde a criação do Sistema Único de Saúde (SUS), as ações de alimentação e nutrição na APS foram impulsionadas pela implantação da Estratégia Saúde da Família (ESF) e ampliadas pelo apoio matricial às equipes de referência com a inserção de equipes, atualmente denominadas Núcleos Ampliados de Saúde da Família e Atenção Básica (NASF-AB) 4,5,6,7.

Em consonância com outras políticas públicas, a Política Nacional de Alimentação e Nutrição (PNAN) reforçou a atuação interdisciplinar, multiprofissional e intersetorial para maior resolubilidade de tais ações. Além disso, situou os cuidados relativos à alimentação e nutrição como parte essencial da atenção nutricional, atribuindo-lhes definições ainda pouco discutidas conceitualmente e suscitou outras noções que emergiram da experiência $8,9,10$.

Considerando a multiplicidade de terminologias e a opacidade de acepções em publicações científicas e oficiais, este estudo compreende como cuidado em alimentação e nutrição o processo que resulta da atuação de múltiplos atores, orientados por diferentes valores, lógicas e intenções, entrelaçados por ações voltadas ao atendimento de necessidades relacionadas à alimentação e nutrição. Tais ações, de algum modo, convergem para a promoção da saúde e prevenção de agravos, tendo como princípios orientadores a produção de vida e qualificação da existência. Assim, a produção do cuidado em alimentação e nutrição invariavelmente lida com imanências como a simultaneidade e indivisibilidade do comer no âmago da relação entre o corpo e a comida, abrangendo, provocando e sendo mobilizado por repercussões fisiológicas e fisiopatológicas, ao tempo em que se relaciona com dimensões sociais, culturais e existenciais.

Tal perspectiva coaduna com o posicionamento de pesquisadores que suscitaram olhares para os espaços micropolíticos de produção do cuidado em saúde. Esse posicionamento epistemológico alinha-se à compreensão de que o estudo das práticas de cuidado pode contribuir para visibilizar elementos e (inter)ações que possibilitem ampliar reflexões sobre os princípios e lógicas que as fundamentam 11,12,13.

Diante do exposto, este estudo busca compreender como se dá o processo de produção do cuidado em alimentação e nutrição no âmbito da APS, com base nas práticas de apoio matricial.

\section{Metodologia}

Esta investigação de natureza socioantropológica em interface com as ciências da saúde, alimentação e nutrição foi realizada por meio de uma etnografia das práticas de cuidado em alimentação e nutrição desenvolvidas na APS.

Pelo ineditismo, singularidade e complexidade das práticas de cuidado, foram eleitas abordagens metodológicas que possibilitassem presenciá-las no momento em que constituíam processos dinâmicos de produção da realidade. Nesse sentido, o estudo associou-se à Teoria Ator-Rede na perspectiva de Mol 11,12,13,14,15,16.

A etnografia oportunizou o convívio com aspectos particulares e específicos do cuidado em alimentação e nutrição, como a sua íntima ligação com os alimentos e com o comer. Assim, o corpo da 
pesquisadora configurou-se como instrumento sensível de acesso à experiência, afetado de modo crescente por entidades humanas e não humanas, engendradas na composição de múltiplas realidades 16 .

Para presenciar o fenômeno em ato, foi necessário circular por diferentes espaços das unidades de saúde da família (USF - salas de reunião e de espera, consultórios, copas) e do território (ruas, praças, domicílios, escolas, locais de comercialização de alimentos) acompanhando o cotidiano de trabalho dos profissionais, principalmente da nutricionista pela estreita relação do cuidado em alimentação e nutrição com o seu núcleo específico do saber 4.

O trabalho de campo foi realizado de abril a agosto de 2018 em duas USF de um município de grande porte do Estado da Bahia, Brasil. Segundo a Secretaria Municipal de Saúde (SMS), o distrito sanitário ao qual pertenciam as USF tinha área estimada de $20,31 \mathrm{~km}^{2}$, com população de aproximadamente 348 mil habitantes, residentes em 68 bairros/localidades muito diversos entre si em termos de distribuição de renda, serviços e infraestrutura urbana.

O NASF-AB era formado por sete mulheres com idades entre 28 e 34 anos. Uma nutricionista, uma psicóloga, duas terapeutas ocupacionais, duas fisioterapeutas e uma assistente social (as três primeiras especialistas em Saúde da Família ou Saúde Coletiva) prestavam suporte clínico-assistencial e técnico-pedagógico a sete equipes de referência, e apoiavam a formação de estudantes e residentes.

No decurso da investigação, a revisão de publicações científicas e oficiais proporcionou uma visão panorâmica de como o tema vem sendo tratado no Brasil e em outros países. Entrevistas semiestruturadas com usuários e profissionais possibilitaram conhecer acepções do cuidado em alimentação e nutrição, inserido em suas trajetórias biográficas. A participação em cursos promovidos pela SMS em parceria com instituições de ensino superior propiciou perceber como nutricionistas com diferentes modalidades de inserção compreendem e lidam com os limites e desafios do trabalho na APS.

As informações produzidas foram registradas em diários de campo, representações cartográficas e arquivos de áudio. O material empírico foi organizado e explorado para a identificação de eixos temáticos. A análise possibilitou a categorização dos dados, com especial atenção às nuances das interações nas práticas de cuidado dentro e fora do ambiente institucional 17.

Os resultados foram apresentados em três categorias. A primeira expõe a multiplicidade de atores e interações em redes para a produção do cuidado em alimentação e nutrição, destacando a contextualização da alimentação nas práticas assistenciais. A segunda discute a heterogeneidade material na mediação do cuidado, destacando a agência da comida e suas implicações. A terceira explora como as apoiadoras matriciais atuavam na dinâmica ordenação das redes de cuidado em alimentação e nutrição, considerando as potencialidades e tensões das relações entre micro e macropolítica.

Prezando pelo caráter polifônico e dialógico da investigação, uma versão preliminar do texto foi apresentada aos participantes, que validaram e ratificaram a interpretação dos resultados. As discussões suscitadas nessa etapa foram importantes para implicá-los no processo interpretativo 18,19 .

Esta pesquisa foi aprovada pela SMS e pelo Comitê de Ética em Pesquisa da Escola de Nutrição da Universidade Federal da Bahia, sob os pareceres no 0100/2017 e no 2.487.375, respectivamente. Os nomes dos participantes e as designações das USF adotados neste texto são fictícios.

\section{Resultados e discussão}

\section{Atores, interações e fluxos na produção do cuidado em alimentação e nutrição}

Os trabalhadores das USF chegavam diariamente trazendo consigo os alimentos que consumiriam ao longo do dia. No início das manhãs, salas e consultórios eram povoados por mochilas, bolsas, garrafas de água e lancheiras térmicas.

O compartilhamento de pequenos lanches durante as reuniões era comum. Em meio à discussão de casos, condutas e questões operacionais, sempre havia ruídos emitidos pela abertura de uma embalagem de biscoitos, perfume de tangerina preenchendo o ambiente. Ao oferecer a vasilha com fatias de bolo de cenoura para a pessoa ao seu lado, a estagiária explicava que era "fácil de fazer" e, em retribuição aos elogios, prometia trazer a receita no dia seguinte. O burburinho e a movimentação gerados pela partilha não causavam incômodo. Eram parte daqueles momentos. 
A comensalidade entremeava atividades laborais e desencadeava diálogos sobre gostos e racionalidades envolvidas nas práticas alimentares. Em uma das conversas que habitualmente sucediam o almoço na sala de reunião da USF Aclive, a psicóloga Marcela mostrou-se favorável à alimentação ayurveda, explicando que se baseava em "uma lógica diferente da nutricional". Pouco depois, enquanto a nutricionista Luna falava sobre o "dia do intensivão", em que se dedicava à preparação e porcionamento dos alimentos que ela e o marido levariam para o trabalho por duas semanas, a terapeuta ocupacional Maya comentou sobre o tempo despendido nesta tarefa, considerando a sua carga horária de trabalho em diferentes instituições: “Ter uma pessoa que cozinha é vida, viu?". Ela sugeriu à colega que buscasse o serviço de congelamento de alimentos durante o período em que estava sobrecarregada com outras atividades. Amalgamadas, as dimensões profissionais e pessoais expunham similitudes e diversidade de modos de inserção da alimentação no cotidiano da vida. As práticas de cuidado em alimentação e nutrição consigo e com outrem se atravessavam 20.

Nos núcleos familiares, as pessoas (fundamentalmente as mulheres) alternavam-se conforme as suas habilidades e se reorganizavam notadamente em caso de vulnerabilidade ou adoecimento. Segundo relatos da sua mãe, quando Joel foi afastado do trabalho como cobrador de ônibus devido a um tumor metastático, foi preciso fazer ajustes. Ela passou a destinar parte da sua renda para a aquisição de alimentos orgânicos e fitoterápicos - prescritos por uma profissional da rede suplementar - cujas compras passaram a ser de responsabilidade do seu outro filho. Ela também assumia o preparo das refeições de Joel e da neta de cinco anos até a noite, quando a nora retornava do trabalho. Essa última incumbia-se do cuidado e das tarefas domésticas nos finais de semana.

Assim como os profissionais, a comunidade cotidianamente lidava com circunstâncias e contingências, que iam desde a redefinição de quem seria responsável pelo preparo do almoço ou da seleção dos alimentos mais adequados para alguém com um problema de saúde, até aquelas decorrentes das limitações de acesso à alimentação, emprego e renda.

Vivendo em bairros populosos, os usuários relatavam a supressão de áreas verdes associando-a à ocupação desordenada e às reformas urbanas. Ainda assim, havia resistência. Em visita à sua microárea, o agente comunitário de saúde (ACS) Luiz mostrou com entusiasmo a caramboleira que pendia sobre o muro de um dos remanescentes quintais nas proximidades da USF Aliança. Diante dos pequenos vasos, no terceiro pavimento da sua modesta casa, a senhora Vitória disse orgulhosa: "Aqui é minha roça!" e, apontando para cada um, explicou: "Aqui é salsa, aqui é babosa, aqui é maria preta, aqui é cebolinha...". Assim como ela, outras mulheres idosas da comunidade que participavam do grupo de convivência da USF Aclive, também cultivavam plantas medicinais e temperos naturais. Uma prática expressiva da preservação de cuidados ancestrais.

$\mathrm{Na}$ época do estudo, o elevado valor da tarifa e a extinção de linhas de transporte coletivo impactavam sobre a mobilidade da população, limitavam o acesso a feiras livres e centros de abastecimento localizados em outros bairros, restringindo a aquisição a estabelecimentos locais de pequeno e médio portes, que praticavam preços elevados e ofereciam alimentos de qualidade regular e variedade restrita.

Por outro lado, foi notória a expansão do comércio informal de alimentos nos dois territórios. Ruas e praças ficaram repletas de vendedores ambulantes, bancas e lonas estendidas sobre as calçadas. Frutas, verduras e legumes coloriam a paisagem, transformavam o espaço público. Dentro do ônibus, que circulava na área da USF Aliança, um homem fazia demonstrações do descascador de legumes para comprovar a praticidade do produto "na promoção". Entretanto, tais presenças expunham um paradoxo.

Essa forma de ampliação do acesso aos alimentos era resultante da busca por outros modos de sobrevivência ante os crescentes níveis de desemprego e defasagem da renda familiar. Assim, usuários, na condição de vendedores ou consumidores, de alguma forma apoiavam-se mutuamente e revelavam a ausência ou insuficiência da atuação do Estado na execução da política de segurança alimentar e nutricional 1 .

Adversidades e potencialidades desse contexto reverberavam nas práticas institucionais de cuidado em alimentação e nutrição. Todos precisavam lidar com lacunas importantes nas redes, que interrompiam ou alteravam fluxos de conexões.

O tema da alimentação e nutrição frequentemente emergia nas práticas assistenciais. Como parte da sua conduta, diferentes profissionais estimulavam o consumo de "alimentos mais naturais" e admoestavam sobre os efeitos da ingestão frequente de alimentos ultraprocessados, em conformidade 
com o Guia Alimentar para a População Brasileira 21. Ademais, a presença dos usuários nas USF e dos profissionais em visitas às microáreas e domicílios promovia o convívio próximo e repercutia nas interações que costumavam partir do recomendado em direção ao possível.

No cuidado aos usuários, o ACS Luiz costumava compartilhar experiências pessoais para o controle do peso corporal com base naquilo que aprendia nos grupos terapêuticos e consultas com a nutricionista Luna. Em visita domiciliar a uma usuária com obesidade e dificuldades de locomoção, ofereceu-se para comprar para ela uma cuscuzeira individual igual à sua, para viabilizar o consumo de um alimento com melhor valor nutricional do que o pão francês. Também costumava sugerir a churrasqueira de fogão para que a linguiça calabresa, uma das preferências alimentares da população local, pudesse ser preparada com menor teor de gorduras.

Para estimular o enriquecimento e variedade dos alimentos, impressões coloridas de Opções de Refeições Saudáveis (última seção do Guia Alimentar) eram demonstradas pela nutricionista, que conversava com os usuários e familiares sobre as refeições, destacando as cores dos alimentos. Em uma conjunção entre corpo e objeto, ela costumava colocar uma das mãos sobre a foto do prato, ocultando os demais alimentos e expondo apenas a salada, que ocupava a outra metade da imagem, fazendo-os perceber a proporção de vegetais que poderia compor o almoço.

Desse modo, o cuidado em alimentação e nutrição era mediado por objetos. Utensílios facilitavam a aplicação de práticas culinárias. Imagens ilustravam a diversidade de possibilidades de escolhas alimentares. Balança, fita métrica inelástica e cadernetas de saúde instrumentalizavam medições corporais. Marcadores de consumo alimentar eram utilizados no monitoramento da alimentação. Somavam-se a esses, banners, folhetos, jogos de tabuleiro, materiais produzidos pelos profissionais e estagiários, quase sempre com recursos próprios para atividades coletivas.

Ao resgatar as suas vivências com a família em um ambiente rural, a assistente social Júlia trazia às discussões aspectos amplos da alimentação, que iam desde noções sobre técnicas agrícolas até o fortalecimento de vínculos afetivos pela produção coletiva e compartilhamento de pratos típicos da região onde morava. Em meio às racionalidades e realidades em interlocução, a comida demonstrava uma materialidade de outra natureza. A sua presença proporcionava fluxos que intencionavam a transposição de espaços e a permanência no tempo, no decurso das vidas, na produção de saúde e na construção de memórias.

\section{"A tapioca vai ser o carboidrato e o ovo a proteína": a comida nas redes}

Os alimentos circulavam pelos espaços. Estavam presentes nas imagens impressas, nos slides produzidos para atividades na sala de reunião, nas narrativas do cotidiano e nas histórias de vida de trabalhadores e usuários, nos aromas emanados da copa da unidade de saúde, nas lancheiras térmicas e nos recipientes trazidos de casa, nos pequenos lanches passados de mão em mão. A sua presença era, a um só tempo, estrutura e dinamicidade.

Entrelaçando as redes e fortalecendo vínculos, a comensalidade que marcava comemorações e ocasiões festivas também sucedia algumas atividades em grupos e, por vezes, provocava conexões que integravam o processo de aprendizagem. O compartilhamento de alimentos especialmente preparados para esse fim trazia à rede novos atores e reconfiguravam as conexões com aqueles que já estavam presentes.

Uma das atividades do grupo sobre diabetes mellitus realizada na USF Aclive foi aberta pela nutricionista Luna: "Fala o seu nome, como é que você veio parar aqui e responde à pergunta". Referia-se às perguntas geradoras sobre modos de se relacionar com a alimentação, que cada pessoa (10 usuários do serviço de saúde, em sua maioria idosos, duas estagiárias de nutrição, dois residentes de medicina, uma médica e a própria nutricionista) retiraria de uma urna. Algumas respostas remetiam ao que sentiam ante as restrições alimentares ("Hoje o que eu odeio é olhar uma torta linda e não poder comer") e aos modos de convívio com o diabetes mellitus, desde o diagnóstico ("Eu vim porque essa diabetes me pegou. Estou aqui toda assustada!").

As estagiárias Eva e Diana apresentaram aos participantes o painel da sua autoria. Alinhadas na parte superior havia tarjetas com os seguintes nomes: "Proteínas", "Carboidratos", "Gorduras", "Fibras", "Doces e Bebidas Açucaradas". Abaixo, outras tarjetas faziam referência às suas funções e impactos sobre os níveis glicêmicos. Assim, a exposição dialogada feita inicialmente pelas estudantes 
explorava e desenvolvia informações como: a ingestão de "proteínas", cuja principal funcionalidade é a "construção muscular", "aumenta lentamente a glicemia".

Em seguida, todos se reuniram em torno da mesa repleta de recortes de imagens de alimentos com o intuito de anexá-los ao painel, conforme a classificação. Contudo, a tarefa proposta gerou muitas dúvidas e certo alvoroço, pois alimentos como a aveia não se encaixavam em uma única categoria. $\mathrm{O}$ seu posicionamento entre as tarjetas ("fibras" e "proteínas") foi a alternativa sugerida por Luna para resolver tal impasse.

Dando continuidade, os participantes foram convidados a deslocar as mesmas figuras para placas de emborrachado, que simulavam pratos das principais refeições (café da manhã, lanche, almoço/jantar). O objetivo era de que exercitassem composições baseando-se na compreensão desenvolvida na etapa anterior: "...para que a gente consiga montar uma refeição mais rica, que seja saborosa e que não impacte muito na glicemia" disse Diana.

Em meio a tal processo, foram sugeridas opções de lanches como "banana com leite, maçã com iogurte natural e crepioca". A fala da médica Lia referente a essa última preparação expunha a lógica que as fundamentava: "A tapioca vai ser o carboidrato e o ovo a proteina". As combinações propostas intencionavam evitar restrições alimentares desnecessárias - comumente realizadas por pessoas com diabetes mellitus - e uma vez consumindo um alimento fonte de carboidrato, que "aumenta rápido a glicemia", manteria a estabilidade relativa da resposta glicêmica no período pós-prandial pela ação retardante da proteína. A produção do cuidado em alimentação e nutrição por meio do controle metabólico evidenciava outra racionalidade presente nas práticas e na fala de Eva: "O segredo da vida, não só da alimentação, é o equilíbrio".

Tais interações promoviam a produção de sentidos e integravam o rol de estratégias de incentivo às associações entre atores na rede. Contudo, a conjunção entre corpos, comida e conhecimento trazia ao processo a intensidade e a potência das conexões provocadas pela experiência do comer.

Ao final da atividade, Luna ofereceu torradas com patê de ricota temperado com alho, tomate, óleo de oliva, orégano, manjericão e outras ervas, que ela mesma havia preparado em casa. Sobre a mesa, os recortes de papel deram lugar à comida. A segunda receita do impresso Sugestões de Receitas Saudáveis que, por vezes, entregava aos usuários no atendimento individualizado estava ali materializada. A descrição do modo de preparo, argumentos de baixo custo, rendimento e praticidade precederam a degustação.

Assim como em outras situações, os usuários eram encorajados a desenvolver o autocuidado, que envolvia além do desenvolvimento do olhar abstrato para os alimentos e para o corpo, o reconhecimento de sentimentos e sensações para lidar de modo mais autônomo com a variabilidade e multiplicidade de demandas no cotidiano da vida. Os profissionais buscavam a complementaridade como um princípio, manejando as divergências de referenciais técnicos e aspectos da realidade para a produção de saúde. Contudo, conciliar diferentes e conflitantes perspectivas não era uma operação simples.

O conhecimento acerca da composição nutricional e dos efeitos dos alimentos sobre os níveis glicêmicos é reconhecidamente útil para instrumentalizar escolhas cotidianas mais autônomas e favoráveis à saúde e à qualidade de vida 22 . Pessoas portadoras ou que convivem com alguém com diabetes têm muitas dúvidas em relação ao que pode ser consumido e criam táticas próprias para conter alterações da glicemia 23 . Além disso, as incertezas que perpassam o cotidiano das práticas alimentares não eram exclusivas de pessoas que vivenciam essa condição clínica.

Contudo, as tentativas de segregação dos alimentos segundo o valor nutricional, funcionalidade e efeitos metabólicos postulados por consensos científicos, como as Diretrizes da Sociedade Brasileira de Diabetes, usadas como referencial para a atividade descrita, não raramente se deparam com a complexidade que extravasa tais demarcações 13,24.

Mesmo sob a forma de imagens impressas, os alimentos atuam. Expressam a sua ambiguidade, resistem e expõem a debilidade das fronteiras que, em vão, tentam contê-los em categorias generalizantes e excludentes. No processo de produção do cuidado, são atores que, assim como a aveia, subvertem a ordem e tensionam a criação de espaços de interseção no interior das tessituras das quais fazem parte.

A contextualização dos alimentos (seja nas refeições, no cotidiano do território, nos sistemas de produção) traz de volta à luz a sua diversidade e o seu caráter social, frequentemente mantidos na opacidade por processos hegemônicos a exemplo da medicalização do corpo e da alimentação 13. 
Nesse cenário, há produções científicas que ao incorporar as dimensões socioambiental e sociocultural aos discursos do campo da nutrição colocam em circulação compreensões, que intencionam o respeito à autonomia e o fomento à emancipação dos sujeitos, acolhendo a diversidade e promovendo a qualificação de práticas de cuidado em alimentação e nutrição 6,8,21 25 .

Nesse sentido, a (re)união dos alimentos segundo lógicas de ordenamento mais maleáveis viabiliza a sua presença em vários lugares, sob diversas combinações. Na medida em que os usuários são estimulados a fazer as suas próprias escolhas alimentares orientadas por critérios que respeitam as singularidades dos modos de vida e reforçam aspectos socioculturais, sujeitos e alimentos mostram-se mais livres, com maior mobilidade e assim potencializam a adaptabilidade das redes.

Ainda assim, os efeitos da alimentação sobre a saúde não saem de cena. O estímulo à entrada de alimentos in natura para a substituição gradativa dos alimentos ultraprocessados e o crescente incentivo ao desenvolvimento de habilidades culinárias têm embasado estratégias metodológicas de Educação Alimentar e Nutricional. Tais modos de abordagem consideram que o atendimento das necessidades nutricionais implica a sua concretização sob a forma de comida 26 . Nesse contexto, as práticas culinárias são também práticas de cuidado em alimentação e nutricional.

Compondo a heterogeneidade dos materiais utilizados como mediadores, a comida se destaca por provocar um tipo singular de experiência. Ao afetar os sentidos e provocar sensações, promove o intenso envolvimento daquele que a tateia, degusta e incorpora em um processo relacional que oportuniza a atribuição de sentidos decorrentes da conjunção corpo/comida 27.

A transformação da ricota fresca em "patê de ricota" aconteceu pela adição de temperos que matizaram cores, multiplicaram sabores, aromas e texturas, fazendo surgir extensões da sua (i)materialidade. Promoveu o surgimento de outro alimento. Criado e compartilhado em um momento de alegria e contentamento. Mais aprazível e, portanto, mais impactante, mais potente para provocar conexões com os corpos, mais diverso, intenso e singular.

Somaram-se ao conhecimento dos efeitos sobre a velocidade de elevação da glicemia e construção muscular e aos argumentos de custo e praticidade, as sensações que a comida era capaz de proporcionar (surpresa, satisfação, conforto, prazer, contentamento), erigindo e reforçando outras bases para as escolhas, afastando-as do paradigma do controle 28.

A atividade foi perpassada por modos normativos de conhecer. A adoção de correlatos institucionais (Guia Alimentar, Diretrizes da Sociedade Brasileira de Diabetes) e materiais (textos, imagens impressas) demonstrava a sua elaboração em consonância com as possibilidades organizacionais. Todavia, as práticas de produção do cuidado em alimentação e nutrição observadas junto ao grupo pesquisado avançavam no sentido de trabalhar com a heterogeneidade material e de experimentar outros estilos de atuar. Como um recurso pujante para provocar reflexões, a comensalidade mobilizava subjetividades pelo uso de modos emocionais e sensoriais de conhecer, aprender e cuidar 29.

Assim, a comida atuava contrapondo dualismos (mente/corpo, natureza/cultura), desfazendo limites (interior/exterior) e desestabilizando distinções (profissionais/usuários). O saber que surgia evocando sentidos acontecia em dobra. Os sujeitos eram atores, público e palco da experiência proporcionada pelo ato de comer 29,30 .

Todos provaram das torradas com patê, do enlace conceitual entre carboidratos e proteínas, que era também o entrelaçamento entre sabores e afetividades, entre descobertas e prazeres. Ao suscitar e engendrar memórias e aprendizagens alimentares, também promoviam a inclusão de novos atores no repertório da alimentação cotidiana. Ao adentrar a rede, o patê de ricota estava ativo no processo de produção de um cuidado vívido e expressivo, pois encontrava no corpo um território aberto a outros modos de conhecer 29,30,31.

\section{"Estando presente": o apoio matricial na coordenação das redes de cuidado em alimentação e nutrição}

As noções de causalidade, que estritamente relacionavam a obesidade ao desequilíbrio energético, estavam presentes nas falas das usuárias, nos programas de TV exibidos na sala de espera, nas conversas entre trabalhadoras e, por vezes, apareciam nos discursos dos profissionais durante as reuniões de matriciamento. 
Ante à ênfase atribuída pela ACS Diná e pela médica Ana ao fato da usuária Aída ter revelado que havia comido um pedaço de bolo, a nutricionista Luna contrapôs a ideia de que o consumo eventual deste alimento era um ato de negligência. Além de questionar se aquele era realmente um problema, narrou um encontro com a usuária chorosa e angustiada por não conseguir perder peso, a despeito das mudanças alimentares. Ao resgatar aspectos do "emaranhado de eventos" (Aída também possuía diabetes mellitus, hipertensão arterial sistêmica, insuficiência cardíaca congestiva, artrose e fascite plantar) relacionados ao processo inflamatório e às limitações de mobilidade, que dificultavam a perda de peso, Luna afirmou: "A intervenção da nutrição sozinha não vai fazer absolutamente nada".

A diversidade de compreensões acerca do caso era expressada desde a análise até as negociações para a definição de abordagens, que considerassem o contexto de vida daquela mulher como ponto de partida. Como Aída havia outras usuárias (sobrecarregadas pelas tarefas domésticas, pelo cuidado às pessoas com adoecimento crônico, vivenciando relacionamentos abusivos, vulnerabilidade social) que pareciam estar envolvidas "em uma teia de problemas".

Diante de realidades complexas, as articulações em parceria com as equipes de referência, familiares e membros da comunidade aconteciam por meio de tentativas de: encaminhá-las a multicentros de saúde e clínicas especializadas pela produção de linhas de cuidado, mantendo-se presentes no acompanhamento do processo terapêutico; trazê-las ao convívio com outros usuários para o compartilhamento de conhecimentos e experiências em espaços de acolhimento, empatia, sociabilidade pelo convite à participação dos grupos (de práticas corporais, de fortalecimento e empoderamento feminino, dentre outros); mover diferentes profissionais das USF para os domicílios a fim de "dar mais suporte", "fazer mais escutas", auxiliando-as na mediação de conflitos e na distribuição do cuidado aos familiares pelo aumento da frequência de visitas; incluir Práticas Integrativas e Complementares para oferecer outros modos de cuidado pela diversificação das formas de atuação das próprias apoiadoras matriciais que possuíam formação em auriculoterapia; ou ainda, afastar as práticas alimentares e a corpulência dos julgamentos morais pelo estímulo a reflexões e realização de ações de educação permanente em saúde sobre alimentação e gordofobia.

As práticas de apoio matricial eram práticas situadas que promoviam e direcionavam múltiplos e repercussivos movimentos, revolvendo e modificando a dinâmica das redes. Esforçando-se mutuamente para criar maneiras específicas de lidar com realidades plurais, respeitando as singularidades dos usuários e dos profissionais de saúde 12 .

Atuações perpassadas por conflitos e divergências que, a todo momento, eram objeto da reflexividade presente nas discussões entre as apoiadoras matriciais e estudantes, como expressa a fala da nutricionista Luna: "É mexer com questões de vida, de estruturação da família, de condição. (...) Tem horas que seu poder se esgota. (...) Nem tudo vai se resolver. A gente vai ter que seguir ofertando, estando presente, dando o cuidado que a gente pode".

Ao promover a ampliação do cuidado em alimentação e nutrição em direção à integralidade, manejavam existências, vínculos e relações familiares, assim como a escassez de recursos financeiros. Lidavam com as limitações da própria atuação diante de realidades refratárias, relativizando a resolubilidade e mantendo o posicionamento ético de acompanhar os sujeitos ao longo da vida, oferecendolhes o cuidado possível 11.

Assim, a produção do cuidado em alimentação e nutrição dimanava da ordenação (constante e sempre provisória) das redes em um processo aberto. Contudo, o uso do prefixo co e do hífen na grafia do termo parece mais adequado para traduzi-lo. Tratava-se da coordenação (profusa e sempre compartilhada) das redes em um processo ressonante, no qual as apoiadoras matriciais estimulavam a inclusão, associação, reposicionamento e mudanças na atuação de múltiplos atores. Simultaneamente, a repercussividade desses movimentos implicava também processos de subjetivação. Experimentando e integrando conexões promotoras de saúde, estabelecendo e fortalecendo vínculos terapêuticos, contribuíam para a adaptabilidade, fluidez e efetividade das tessituras, que também as transformavam $11,16,29,30,32$.

É importante destacar que a implantação do apoio matricial trouxe à APS profissionais com a proposta de que realizassem a cogestão e qualificação do cuidado, colocando-os na interface entre usuários, famílias, comunidade, equipes de referência, unidades assistenciais, unidades de ensino, dentre outros. Tal inserção oportunizou a democratização de expertises e o desenvolvimento de habilidades para atuar em redes. Entretanto, havia outros desafios relacionados à gestão do SUS 5,11,15. 
Em paralelo às ações institucionais para a ampliação da cobertura populacional da ESF no município pesquisado, os trabalhadores da saúde vivenciavam repercussões do financiamento insuficiente e, assim como servidores municipais de outros setores como a Educação, paralisaram parcialmente as atividades para protestar pelo respeito às regras de remuneração e planos de carreira.

Nesse mesmo período, com base nas mudanças instituídas pela Política Nacional de Atenção Básica 10, a SMS redefiniu as atividades assistenciais, estabelecendo o aumento do número de atendimentos individuais dos NASF-AB. Tais mudanças ocorreram a despeito da indisponibilidade de consultórios e dos questionamentos dos profissionais das USFs Aclive e Aliança sobre a resolutividade dessa forma de trabalho, que os afastava da potência dos espaços coletivos. Foram decisões que priorizaram a produtividade e reforçaram aspectos do modelo tradicional de atenção, pouco compatíveis com os princípios e potencialidades que fundamentaram a implantação da ESF e do apoio matricial 11,33.

As apoiadoras matriciais, que participaram deste estudo, vivenciavam tensões inerentes às relações entre micropolítica e macropolítica. Como integrantes das redes, posicionavam-se. Coordenando as redes, auxiliavam outros atores no seu próprio posicionamento. Mas também pelo seu caráter constitutivo eram posicionadas. Em certa medida, reguladas em seus modos de atuar.

Contudo, de acordo com os achados do campo, o cerceamento das possibilidades de articulação e retrações eram potencialmente propulsoras da invenção de novos arranjos, de novos fluxos. A imanência e ubiquidade das tessituras dinâmicas - entre pessoas, lógicas, racionalidades, corpos e coisas presentes e agentes nos atos de cuidar - eram expressões da sua associação com a manutenção da vida e produção da existência. As redes de cuidado em alimentação e nutrição demonstraram ser formações rizomáticas.

\section{Considerações finais}

Sob inspiração das perspectivas teórico-filosóficas de Deleuze e Guattari e da Teoria Ator-Rede, esta investigação identificou que a produção do cuidado em alimentação e nutrição emergia de redes múltiplas e interligadas. Construções imanentes formadas por arranjos provisórios que, a todo momento, integravam atores (humanos, desde o nascimento; não humanos, desde a produção, inclusive alimentos) em fluxos constantes de conexões entre si e com o mundo. Interações que os modificavam (atores, redes e mundos) incessantemente.

Baseando-se nessa perspectiva, processos dinâmicos e simultâneos de atuações repercussivas e ressonantes tornam-se visíveis. Tal percepção pode contribuir para posicionamentos mais profícuos, que transpõem a díade profissional/usuário em relação com as Redes de Atenção à Saúde e avançam no sentido da corresponsabilidade.

Sabendo-se atores, os sujeitos podem se situar melhor nas redes e atuar de modo integrado, segundo princípios éticos, desenvolvendo posturas mais politizadas e conscientes que relacionam as práticas no âmbito privado à soberania alimentar e aos sistemas de produção economicamente justos e sustentáveis. Ao tornarem-se mais ativos e conscientes, é possível que se conectem de outros modos com os alimentos, entendendo que a alimentação está ligada a outros direitos humanos fundamentais - como saúde, trabalho e educação - e assim se posicionar na luta pela implantação e execução de políticas públicas que oportunizem a garantia da Segurança Alimentar e Nutricional à população.

Em consonância com a noção de coisa de Tim Ingold 31, este texto passa a habitar o mundo. Ao integrar fluxos de interações passa a constituir e a ser constituído pelas reflexões e conexões que provoca. Ao adentrar o debate científico fomenta a continuidade, a diversidade de pesquisas sobre o cuidado em alimentação e nutrição como um constructo social, como algo que emerge nas tessituras dos encontros dos sujeitos entre si e com o mundo, como uma força produtora da vida. 


\section{Colaboradores}

L. M. Magalhães atuou na concepção e desenvolvimento do projeto de pesquisa, análise, interpretação dos dados e elaboração do manuscrito. L. AmparoSantos orientou a elaboração e o desenvolvimento do projeto, colaborou com a revisão crítica do conteúdo e aprovação da versão final do manuscrito.

\section{Informações adicionais}

ORCID: Lilian Miranda Magalhães (0000-00034964-052X); Lígia Amparo-Santos (0000-00026925-6421).

\section{Agradecimentos}

Ao Conselho Nacional de Desenvolvimento Científico e Tecnológico (processo no 408611/2017-0) e à Fundação de Amparo à Pesquisa da Bahia (processo no 5054/2017), também pelo financiamento de bolsa de estudo.

\section{Referências}

1. Reynolds R, Dennis S, Hasan I, Slewa J, Chen $\mathrm{W}$, Tian D, et al. A systematic review of chronic disease management interventions in primary care. BMC Fam Pract 2018; 19:11.

2. Botelho FC, França Junior I. Como a atenção primária à saúde pode fortalecer a alimentação adequada enquanto direito na América Latina? Rev Panam Salud Pública 2018; 42:e159.

3. Hone T, Macinko J, Millett C. Revisiting AlmaAta: what is the role of primary health care in achieving the Sustainable Development Goals? Lancet 2018; 392:1461-72.

4. Departamento de Atenção Básica, Secretaria de Atenção à Saúde, Ministério da Saúde. Diretrizes do NASF: Núcleo de Apoio Saúde da Família. Brasília: Ministério da Saúde; 2010. (Série A. Normas e Manuais Técnicos) (Cadernos de Atenção Básica, 27).

5. Cunha GT, Campos GWS. Apoio matricial e atenção primária em saúde. Saúde Soc 2011; 20:961-70.

6. Departamento de Atenção Básica, Secretaria de Atenção à Saúde, Ministério da Saúde. Contribuições dos núcleos de apoio à saúde da família para a atenção nutricional. Brasília: Ministério da Saúde; 2017.

7. Jaime PC, Delmuè DCC, Campello T, Silva DO, Santos LMP. Um olhar sobre a agenda de alimentação e nutrição nos trinta anos do Sistema Único de Saúde. Ciênc Saúde Colet 2018; 23:1829-36.

8. Departamento de Atenção Básica, Secretaria de Atenção à Saúde, Ministério da Saúde. Política Nacional de Alimentação e Nutrição. Brasília: Ministério da Saúde; 2012.

9. Rodrigues DCM, Bosi MLM. O lugar do nutricionista nos Núcleos de Apoio à Saúde da Família. Rev Nutr 2014; 27:735-46.

10. Ministério da Saúde. Portaria no 2.436, de 21 de setembro de 2017. Aprova a Política Nacional de Atenção Básica, estabelecendo a revisão de diretrizes para a organização da atenção básica. Diário Oficial da União 2017; 22 set.

11. Mol A. The logic of care: health and the problem of patient choice. New York: Routledge; 2008.

12. Franco TB, Andrade ST, Ferreira VSC. A produção subjetiva do cuidado: cartografias da estratégia de Saúde da Família. São Paulo: Editora Hucitec; 2009.

13. Yates-Doerr E. The opacity of reduction: nutritional black-boxing and the meanings of nourishment. Food, Culture and Society 2012; 15:293-313.

14. Deleuze G, Guattari F. Mil platôs - capitalismo e esquizofrenia. Rio de Janeiro: Editora 34; 1995.

15. Mendonça MHM, Matta GC, Gondim R, Giovanella $\mathrm{L}$, organizadores. Atenção primária à saúde no Brasil: conceitos, práticas e pesquisa. Rio de Janeiro: Editora Fiocruz; 2018. 
16. Mol A. Actor-Network Theory: sensitive terms and enduring tensions. Kolner Z Soz Sozpsychol 2010; 50:253-69.

17. Corbin J, Strauss A. Grounded theory research: procedures, canons and evaluative criteria. $\mathrm{Z}$ Soziol 1990; 19:418-27.

18. Malterud K. Qualitative research: standards, challenges, and guidelines. Lancet 2001; 358:483-8

19. Trad LAB. Trabalho de campo, narrativa e produção de conhecimento na pesquisa etnográfica contemporânea: subsídios ao campo da saúde. Ciênc Saúde Colet 2012; 17:627-33.

20. Palmieri C. Being a caring "presence": caring for the care experience. Encyclopaideia 2014; 18:64-73.

21. Departamento de Atenção Básica, Secretaria de Atenção à Saúde, Ministério da Saúde, Ministério da Saúde. Guia alimentar para a população brasileira. Brasília: Ministério da Saúde; 2014.

22. Weaver RR, Lemonde M, Payman N, Goodman WM. Health capabilities and diabetes self-management: the impact of economic, social, and cultural resources. Soc Sci Med 2014; 102:58-68.

23. Guell C. Self-care at the margins meals and meters in migrants' diabetes tactics. Med Anthropol Q 2012; 26:518-33.

24. Deleuze G. Diferença e repetição. Rio de Janeiro: Editora Graal; 2006.

25. Oliveira MS, Silva-Amparo L. Food-based dietary guidelines: a comparative analysis between the Dietary Guidelines for the Brazilian Population 2006 and 2014. Public Health Nutr $2018 ; 21: 210-7$
26. Diez-Garcia RW, Castro IRR. A culinária como objeto de estudo e de intervenção no campo da Alimentação e Nutrição. Ciênc Saúde Colet 2011; 16:91-8.

27. Mann A, Mol A, Satalkar P, Savirani A, Selim $\mathrm{N}$, Sur M, et al. Mixing methods, tasting fingers: Notes on an ethnographic experiment. HAU: Journal of Ethnographic Theory 2011; $1: 221-43$.

28. Vogel E, Mol A. Enjoy your food: on losing weight and taking pleasure. Sociol Health Illn 2014; 36:305-17.

29. Law J, Ruppert E. Modes of knowing: resources from the Baroque. Manchester: Mattering Press; 2016.

30. Bondía JL. Notas sobre a experiência e o saber da experiência. Revista Brasileira de Educação 2002; (19):20-8.

31. Ingold $T$. Trazendo as coisas de volta à vida: emaranhados criativos num mundo de materiais. Horizontes Antropológicos 2012; 18:2544.

32. Franco TB. Trabalho criativo e cuidado em saúde: um debate a partir dos conceitos de servidão e liberdade. Saúde Soc 2015; 24:102-14.

33. Melo EA, Mendonça MHM, Oliveira JR, Andrade GCL. Mudanças na Política Nacional de Atenção Básica: entre retrocessos e desafios. Saúde Debate 2018; 42 Suppl 1:38-51. 


\section{Abstract}

This ethnographic study aimed to understand the production process in food and nutritional care in the setting of primary healthcare, based on interconsultation support practices. Fieldwork was conducted in two family health units and their respective territories, together with the team from the Expanded Center for Family Health and Basic Care. References for the data analysis were Deleuze and Guattari, Túlio Batista Franco, and researchers associated with Actor-Network Theory such as Annemarie Mol and John Law. The study found that the production of food and nutritional care emerged from links between multiple actors in dynamic and interconnected networks. The practices of care proved to be strongly linked to food's modes of insertion in the daily routines of health professionals and users, revealing paradoxes in the relations of mutual support and expansion of access to food in the territories. Comprising the material heterogeneity in the mediation of interactions, food has an outstanding capacity to spawn connections. Sharing meals mobilized subjectivities through the use of emotional and sensory modes of knowing, learning, and providing care. Experiencing inherent tensions, the relations between micro and macro policy, inter-consultation supporters, together with the other actors, coordinated the networks for the production of food and nutritional care in an open, dynamic, provisional, profuse, and shared process. This understanding can contribute to more active and conscientious positions that move towards shared responsibility in the struggle for the implementation and execution of public policies that guarantee the population's food and nutritional security.

Diet, Food and Nutrition; Primary Healthcare; Health Education

\section{Resumen}

Este estudio etnográfico tuvo como objetivo comprender el proceso de producción del cuidado en alimentación y nutrición en el ámbito de la atención primaria de la salud, a partir de las prácticas de apoyo matricial. El trabajo de campo se realizó en dos unidades de salud de la familia y sus respectivos territorios, junto al equipo del Núcleo Ampliado de Salud de la Familia y Atención Básica. Los datos se analizaron en interlocución con Deleuze y Guattari, Túlio Batista Franco e investigadores vinculados a la Teoría del ActorRed como Annemarie Mol y John Law. La investigación identificó que la producción del cuidado en alimentación y nutrición emergía del entrelazamiento de múltiples actores en redes dinámicas e interrelacionadas. Las prácticas de cuidado se mostraron fuertemente vinculadas a los modos de inserción de la alimentación en el día a día de profesionales y usuarios, exponiendo paradojas en las relaciones de apoyo mutuo y ampliación del acceso a alimentos en los territorios. Componiendo la heterogeneidad material en la mediación de las interacciones, la comida se destacaba por la potencia en provocar conexiones. La comensalidad movilizaba subjetividades por el uso de modos emocionales y sensoriales de conocer, aprender y cuidar. Viviendo tensiones inherentes a las relaciones entre micropolitica y macropolítica, los apoyos matriciales, en conjunto con los demás actores, coordinaban las redes para la producción del cuidado en alimentación y nutrición en un proceso abierto, dinámico, provisional, profuso y compartido. Tal comprensión puede contribuir a posiciones más activas y conscientes, que avanzan en el sentido de la corresponsabilidad en la lucha por la implementación y ejecución de políticas públicas que tengan como oportunidad la garantía de la Seguridad Alimentaria y Nutricional para la población.

Nutrición, Alimentación y Dieta; Atención

Primaria de Salud; Educación en Salud
Recebido em 05/Jul/2019

Versão final reapresentada em 02/Jan/2020

Aprovado em 07/Jan/2020 